Article

\title{
Novel Site-Specific Fatty Chain-Modified GLP-1 Receptor Agonist with Potent Antidiabetic Effects
}

\author{
Xia Zhong ${ }^{1,2, *,+}$, Zhu Chen ${ }^{2,3,+}$, Qiong Chen ${ }^{2}$, Wei Zhao ${ }^{2}$ and Zhi Chen ${ }^{3}$ \\ 1 College of Life Science and Technology, Jinan University, Guangzhou 510000, China \\ 2 Reyoung Biopharmaceuticals Co., Ltd, Suzhou 215000, China; Zchen@163.com (Z.C.); \\ qchen0862@yeah.net (Q.C.); zwei1008@163.com (W.Z.) \\ 3 East China University of Science and Technology, Shanghai 200000, China; Paulchan121@outlook.com \\ * Correspondence: x_zhong@outlook.com; Tel.: +86-15521098097 \\ + These authors contributed equally to this work.
}

Received: 16 January 2019; Accepted: 15 February 2019; Published: 21 February 2019

check for updates

\begin{abstract}
Glucagon-like peptide-1 receptor (GLP-1R) agonists have emerged as treatment options for type 2 diabetes mellitus (T2DM). Here, we designed a high-throughput GLP-1R extracellular domain (ECD)-based system that enabled the screening of high-potency receptor-biased GLP-1R agonists demonstrating new pharmacological virtues. Firstly, six 12-mer peptides (termed PEP01-06), screened from a large phage displayed peptide library were fused to the N-terminus of Exendin- 4 (29-39) to generate PEP07-12. By the use of four lysine-altered PEP07 (PEP13-16) as the starting point, a series of fatty chain conjugates (PEP17-20) were synthesized and evaluated by in vitro GLP-1R-based cell assays. In addition, the acute and long-term in vivo effects on diet-induced obesity (DIO) mice were further evaluated. All four conjugates showed good receptor activation efficacy, and PEP20 was selected to undergo further assessment. Preclinical experiments in DIO mice demonstrated that PEP20 had significant insulinotropic activities and glucose-lowering abilities. Moreover, a prolonged antidiabetic effect of PEP20 was also observed by the hypoglycemic test in DIO mice. Furthermore, long-term treatment with PEP20 achieved beneficial effects on the food intake, weight gain, hemoglobin $\mathrm{A} 1 \mathrm{C}$ ( $\mathrm{HbA1C}$ ) lowering activity, and glucose tolerance compared with the control and was similar to the Liraglutide. In conclusion, PEP20, a GLP-1R ECD-biased agonist, may provide a novel therapeutic approach to T2DM.
\end{abstract}

Keywords: Glucagon-like peptide-1 receptor; extracellular domain; Exendin-4; fatty chain; antidiabetic effects

\section{Introduction}

Type 2 diabetes mellitus (T2DM) is a complex metabolic disorder characterized by hyperglycemia arising from insufficient insulin secretion and insulin resistance [1,2]. Glucagon-like peptide-1 (GLP-1) is a 30-amino-acid peptide hormone secreted from gut endocrine L-cells in response to nutrient ingestion, and plays an important role in glucose homeostasis and nutrient metabolism [3-5]. GLP-1 lowers postprandial glucose excursion by potentiating glucose stimulated insulin secretion from pancreatic B cells in a glucose-dependent mode. In addition, GLP-1 outperforms other oral hypoglycemic agents in promoting gastric emptying, weight loss and increasing insulin sensitivity in peripheral tissues. Hence, GLP-1-based therapies represent a strategy for the treatment of T2DM [6-8]. For example, Exendin-4, a 53\% homology with native GLP-1, is a clinically-approved full agonist with a stronger affinity for GLP-1R and longer in vivo half-life [9-12].

GLP-1, or Exendin-4, exerts its action through the GLP-1R, which is expressed in a number of organs, including the pancreas, the central nervous system and the peripheral tissues. GLP-1R, 
is defined by seven transmembrane helices, an extracellular $\mathrm{N}$ terminus, and an intracellular $\mathrm{C}$ terminus, which is ligand binding via the extracellular and intracellular face, respectively, belongs to family B1 of the seven-transmembrane G protein-coupled receptors [13-17]. Both GLP-1 and Exenind-4 interact with the GLP-1R by binding multiple extracellular contact points to induce receptor signaling. Glucagon-like peptide-1 receptor extracellular domain (ECD), as an "addinity trap" to sense the GLP-1 or its analogs outside of the cell, leads to an elevation of cyclic adenosine monophosphate (cAMP), modulates intracellular calcium concentration and induces b-arrestin recruitment, which plays an important role in insulin synthesis and release of insulin in a glucose-dependent mode [18-20]. X-ray crystal structures of Exendin-4 and GLP-1 bound to the ECD confirm the "affinity trap" hypothesis showing the C-terminal $\alpha$-helical region of GLP-1 or Exendin-4 is positioned within a binding cleft of the N-terminal ECD [21,22]. Despite the weaker affinity of GLP-1 for isolated ECD $\left(\mathrm{IC}_{50} \sim 100 \mathrm{nM}\right)$ than the full-length GLP-1R ( $\left.\mathrm{IC}_{50} \sim 1 \mathrm{nM}\right)$, GLP-1R ECD still could be used as a useful high throughput in vitro assessment methods for screening the GLP-1R agonists [23,24].

In this work, we developed a GLP-1R ECD-based system to screen the large phage displayed 12-mer peptide library with the aim of identifying receptor-biased GLP-1R agonists. Then six peptides were fused to the Exendin-4 (29-39) to generate the hybrid ones with higher affinity for GLP-1R. We identified the selected one such hybrid peptide and then covalent coupled to fatty chain, termed PEP20. Moreover, both the in vitro and in vivo characteristics of PEP20 were investigated to identify its antidiabetic and obesity properties.

\section{Results}

\subsection{Discovery of Novel Glucagon-Like Peptide-1 Receptor Agonists}

To discover the potential peptides with high affinity for GLP-1R a commercial peptide library, designed based on M13 phage and containing linear 12 random peptide sequences, was subjected for biopanning the GLP-1R ECD-binding domain (Figure 1). Six peptides, with high affinity for GLP-1R ECD, were selected from peptide libraries using a phage display technique and defined as PEP01-PEP06.

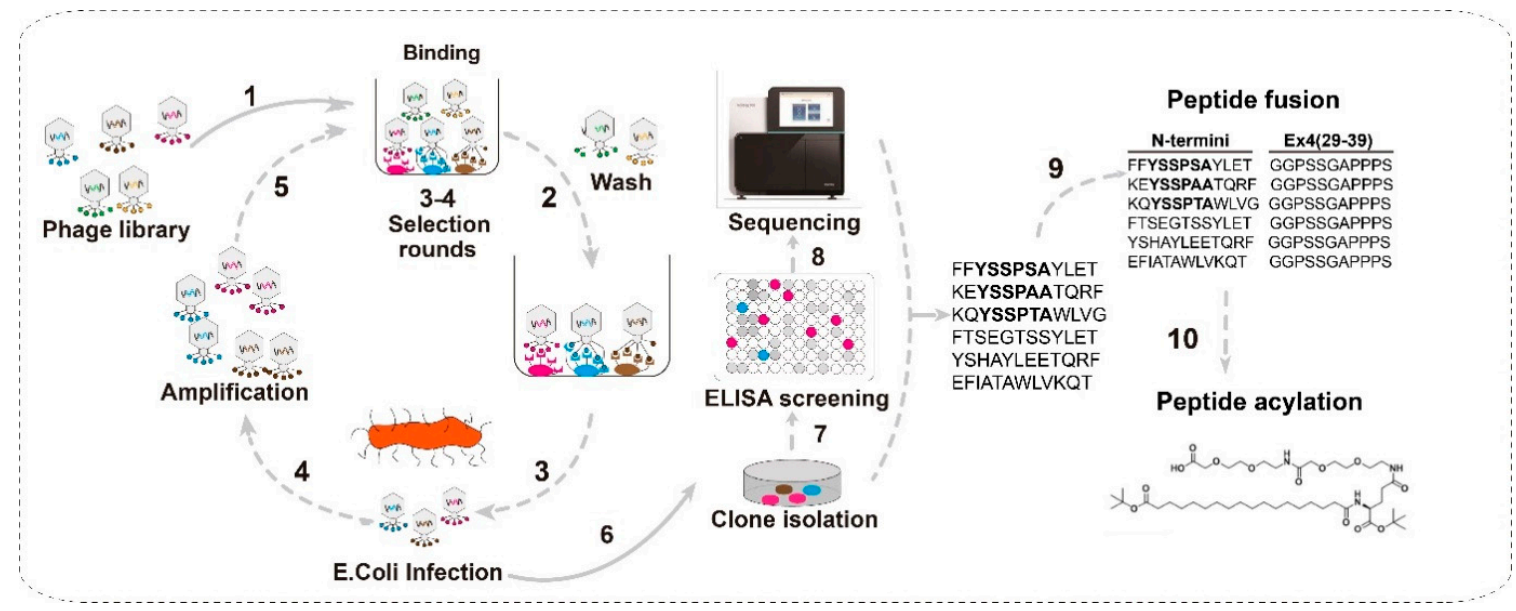

Figure 1. Selection of Glucagon-like peptide-1 receptor agonists from peptide libraries.

The sequence GGPSSGAPPPS of Exendin-4, as the key C-terminal region which could enhance its affinity for the receptor, interacts with the $\mathrm{N}$ terminus ECD of GLP-1R, facilitating the receptor activation $[20,25]$. On basis of these Exendin-4 structure-activity insights, the selected short GLP-1R agonists (PEP01-06) peptide library consisting of random 12 amino acids fused to Exendin-4(29-39) was generated, which accounted for the increased receptor activation activity of Exendin-4 compared with GLP-1. As a result, six hybrid peptides termed PEP07-PEP12 were constructed after the fusion of 
two sequences. All of these hybrid peptides were identified to exhibit higher affinity for GLP-1R ECD after fusion (Table 1).

SPR measurements showed a significant higher binding affinity of PEP07 for GLP-1R ECD than either peptide, yielding a $\mathrm{K}_{\mathrm{d}}$ of $24 \mathrm{nM}$. Considering the predictable short half-life in vivo, these candidate molecules still should be further modified to enhance bioavailability. Therefore, PEP07 was selected as the lead peptides for further acylation.

Table 1. The binding affinity of peptide 01-12 for Glucagon-like peptide-1 receptor extracellular domain.

\begin{tabular}{cccccc}
\hline Peptide & Sequence & $\mathbf{K}_{\mathbf{d}}(\boldsymbol{\mu M})$ & Peptide & Sequence & $\mathbf{K}_{\mathbf{d}}(\boldsymbol{\mu M})$ \\
\hline 01 & FFYSSPSAYLET & 0.74 & 07 & FFYSSPSAYLET GGPSSGAPPPS & 0.024 \\
02 & KEYSSPAATQRF & 1.05 & 08 & KEYSSPAATQRF GGPSSGAPPPS & 0.151 \\
03 & KQYSSPTAWLVG & 1.75 & 09 & KQYSSPTAWLV GGPSSGAPPPS & 0.253 \\
04 & FTSEGTSSYLET & 3.99 & 10 & FTSEGTSSYLET GGPSSGAPPPS & 2.998 \\
05 & YSHAYLEETQRF & 2.21 & 11 & YSHAYLEETQRF GGPSSGAPPPS & 1.252 \\
06 & EFIATAWLVKQT & 2.59 & 12 & EFIATAWLVKQT GGPSSGAPPPS & 1.092 \\
\hline
\end{tabular}

\subsection{Synthesis and Characterization of the Fatty Chain-Modified Hybrid Glucagon-Like Peptide-1 Receptor Agonists}

Lysine scanning mutagenesis was performed to determine a suitable acylation site. The four consecutive amino acids (YLET) of PEP07 were individually replaced by lysine to generate four peptides (Figure 2, named PEP13-16). The associating affinity of Lys-PEP07 peptides for GLP-1R ECD are shown in Table 2. Although lysine mutagenesis on a few sites led to decreased affinity (e.g., PEP15), lysine replacement at some sites did not affect the receptor binding potency, such as PEP14 and PEP16. Particularly, PEP16, with highest associating affinity for GLP-1R ECD $(25 \mathrm{nM})$, was selected for further site specific acylation.
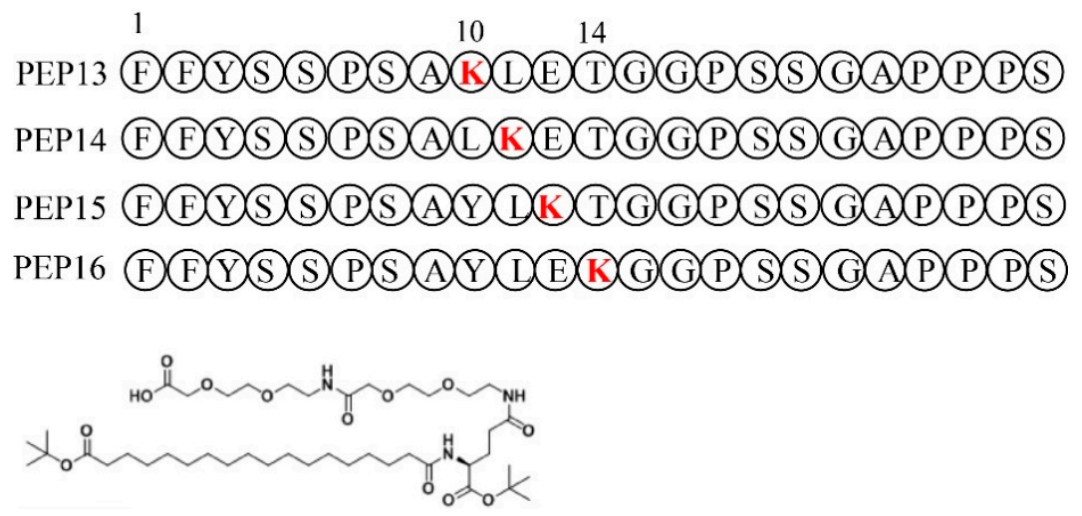

Figure 2. Structure of fatty chain-modified Glucagon-like peptide-1 receptor agonist conjugates.

Table 2. The binding affinity of PEP13-16 for Glucagon-like peptide-1 receptor extracellular domain.

\begin{tabular}{cccc}
\hline Peptide & Sequence & $\begin{array}{c}\mathbf{K}_{\mathbf{d}}(\boldsymbol{\mu M}) \\
\text { (Unconjugated) }\end{array}$ & $\begin{array}{c}\mathbf{K}_{\mathbf{d}}(\boldsymbol{\mu M} \mathbf{M}) \\
(\text { Conjugated) }\end{array}$ \\
\hline PEP13 & FFYSS PSAKLL ETGGP SSGAP PPS & 0.098 & 0.158 \\
PEP14 & FFYSS PSAYK ETGGP SSGAP PPS & 0.053 & 0.062 \\
PEP15 & FFYSS PSAYL KTGGP SSGAP PPS & 0.033 & 0.091 \\
PEP16 & FFYSS PSAYL EKGGP SSGAP PPS & 0.023 & 0.025 \\
\hline
\end{tabular}

As shown in Table 3, the selected lysine-altered peptides (PEP13-16) were reacted with fatty chains to give four fatty chain-modified conjugates (PEP17-20) which were purified by preparative reverse phase high-performance liquid chromatography (RP-HPLC) and further identified by liquid chromatrography tandem mass spectrometry (LC-MS). 
Table 3. Characterization of the fatty chain-modified Glucagon-like peptide-1 receptor agonists.

\begin{tabular}{|c|c|c|c|c|c|c|c|}
\hline \multirow{2}{*}{ Peptide } & \multirow{2}{*}{$\begin{array}{l}\text { Retention } \\
\text { (min) }\end{array}$} & \multicolumn{2}{|c|}{ Molecular Mass } & \multirow{2}{*}{ Conjugated-Peptide } & \multirow{2}{*}{$\begin{array}{l}\text { Retention } \\
\text { (min) }\end{array}$} & \multicolumn{2}{|c|}{ Molecular Mass } \\
\hline & & Calculated & Found & & & Calculated & Found \\
\hline \multirow[t]{2}{*}{ PEP13 } & 5.62 & {$[\mathrm{M}+3 \mathrm{H}]^{+} 756.2$} & 756.3 & PEP17 & 6.65 & {$[\mathrm{M}+3 \mathrm{H}]^{+} 989.0$} & 989.2 \\
\hline & & {$[\mathrm{M}+4 \mathrm{H}]^{+} 567.1$} & 567.2 & & & {$[\mathrm{M}+4 \mathrm{H}]^{+} 741.8$} & 741.9 \\
\hline \multirow{2}{*}{ PEP14 } & 5.46 & {$[\mathrm{M}+3 \mathrm{H}]^{+} 772.8$} & 772.9 & PEP18 & 6.39 & {$[\mathrm{M}+3 \mathrm{H}]^{+} 1005.6$} & 1005.8 \\
\hline & & {$[\mathrm{M}+4 \mathrm{H}]^{+} 579.6$} & 579.5 & & & {$[\mathrm{M}+4 \mathrm{H}]^{+} 754.2$} & 754.5 \\
\hline \multirow[t]{2}{*}{ PEP15 } & 5.72 & {$[\mathrm{M}+3 \mathrm{H}]^{+} 767.5$} & 767.4 & PEP19 & 6.81 & {$[\mathrm{M}+4 \mathrm{H}]^{+} 1000.3$} & 1000.1 \\
\hline & & {$[\mathrm{M}+4 \mathrm{H}]^{+} 575.6$} & 575.5 & & & {$[\mathrm{M}+3 \mathrm{H}]^{+} 750.3$} & 750.1 \\
\hline \multirow[t]{2}{*}{ PEP16 } & 5.23 & {$[\mathrm{M}+3 \mathrm{H}]^{+} 776.8$} & 776.6 & PEP20 & 5.97 & {$[\mathrm{M}+3 \mathrm{H}]^{+} 1009.4$} & 1009.1 \\
\hline & & {$[\mathrm{M}+4 \mathrm{H}]^{+} 582.6$} & 582.5 & & & {$[\mathrm{M}+4 \mathrm{H}]^{+} 757.1$} & 756.9 \\
\hline
\end{tabular}

\subsection{In Vitro Activity of Hybrid Glucagon-Like Peptide-1 Receptor Agonist}

As shown in Table 4, slight reduction in the activation potency was observed due to the fatty chain modifications. Notably, the modified conjugates (PEP17 and PEP18), close to a consensus motif of "YSSPXA", which could enhance its affinity for the receptor, were less potent to the modified conjugates, such as PEP20, which were relatively far away from the probable active domain. Since the $\mathrm{EC}_{50}$ of PEP20 in both human or mouse GLP-1R activation was similar to the reference peptide Exendin-4, and better than the native GLP-1 or Liraglutide, we selected this molecule for the further efficacy evaluation in vivo.

Table 4. In vitro pharmacological characterization of the GLP-1 Receptor peptide.

\begin{tabular}{ccccc}
\hline \multirow{2}{*}{ Peptide } & \multicolumn{2}{c}{ Human GLP-1R } & \multicolumn{2}{c}{ Mouse GLP-1R } \\
\cline { 2 - 5 } & EC $_{\mathbf{5 0}} \mathbf{( n M )}$ & $\mathbf{E m a x}(\mathbf{\%})$ & $\mathbf{E C}_{\mathbf{5 0}} \mathbf{( n M )}$ & Emax (\%) \\
\hline Exendin-4 & $0.052 \pm 0.012$ & $100 \pm 2.5$ & $0.076 \pm 0.008$ & $100 \pm 1.1$ \\
Liraglutide & $0.282 \pm 0.041$ & $81 \pm 5.2$ & $0.185 \pm 0.039$ & $89 \pm 2.1$ \\
GLP-1 & $0.552 \pm 0.89$ & $76 \pm 7.2$ & $0.322 \pm 0.199$ & $81 \pm 4.6$ \\
PEP13 & $0.064 \pm 0.022$ & $96 \pm 4.1$ & $0.051 \pm 0.009$ & $110 \pm 9.4$ \\
PEP14 & $0.051 \pm 0.008$ & $105 \pm 9.2$ & $0.034 \pm 0.002$ & $150 \pm 10.9$ \\
PEP15 & $0.451 \pm 0.121$ & $78 \pm 9.1$ & $0.457 \pm 0.085$ & $73 \pm 6.4$ \\
PEP16 & $0.111 \pm 0.054$ & $92 \pm 7.1$ & $0.101 \pm 0.012$ & $93 \pm 9.3$ \\
PEP17 (Conjugated) & $0.412 \pm 0.019$ & $79 \pm 6.4$ & $0.678 \pm 0.012$ & $68 \pm 5.9$ \\
PEP18 (Conjugated) & $0.391 \pm 0.081$ & $78 \pm 6.4$ & $0.351 \pm 0.044$ & $78 \pm 3.5$ \\
PEP19 (Conjugated) & $0.152 \pm 0.092$ & $89 \pm 6.2$ & $0.212 \pm 0.102$ & $83 \pm 3.2$ \\
PEP20 (Conjugated) & $0.062 \pm 0.011$ & $98 \pm 8.1$ & $0.051 \pm 0.003$ & $99 \pm 7.2$ \\
\hline
\end{tabular}

\subsection{Glucoregulatory and Insulin Secretion Assay}

Oral glucose tolerance test was performed at $1 \mathrm{~h}$ after diet-induced obesity (DIO) mice received $25 \mathrm{nmol} / \mathrm{kg}$ PEP20, Exendine-4 or Liraglutide to evaluate the glucose-lowering and insulinotropic effects (Figure 3A,B). Half an hour after a glucose challenge, the blood glucose level (BGL) in the vehicle treated group rapidly increased to $23.6 \pm 3.1 \mathrm{mmol} / \mathrm{L}$ while in the PEP20-, Exendin-4-, and Liraglutide-treated mice, dramatically reduced to $10.1,9.8$, and $12.2 \mathrm{mmol} / \mathrm{L}$, respectively. Moreover, a glucose-lowering percentage of $60.2 \%$ was showed in PEP20 treated group, while the Exendine- 4 or Liraglutide group showed a reduction of $66.1 \%$ or $46.1 \%$, respectively, compared with the vehicle control group.

Similar time courses for plasma insulin concentrations in PEP20, Liraglutide or Exendin-4 treated group were observed and all plasma insulin concentrations from 15 to 60 min were significantly greater than those of the control group. In particular, PEP20 showed similar and comparable insulin secretion promoting ability than Exendin-4 and Liraglutide, respectively (Figure 3C,D). 

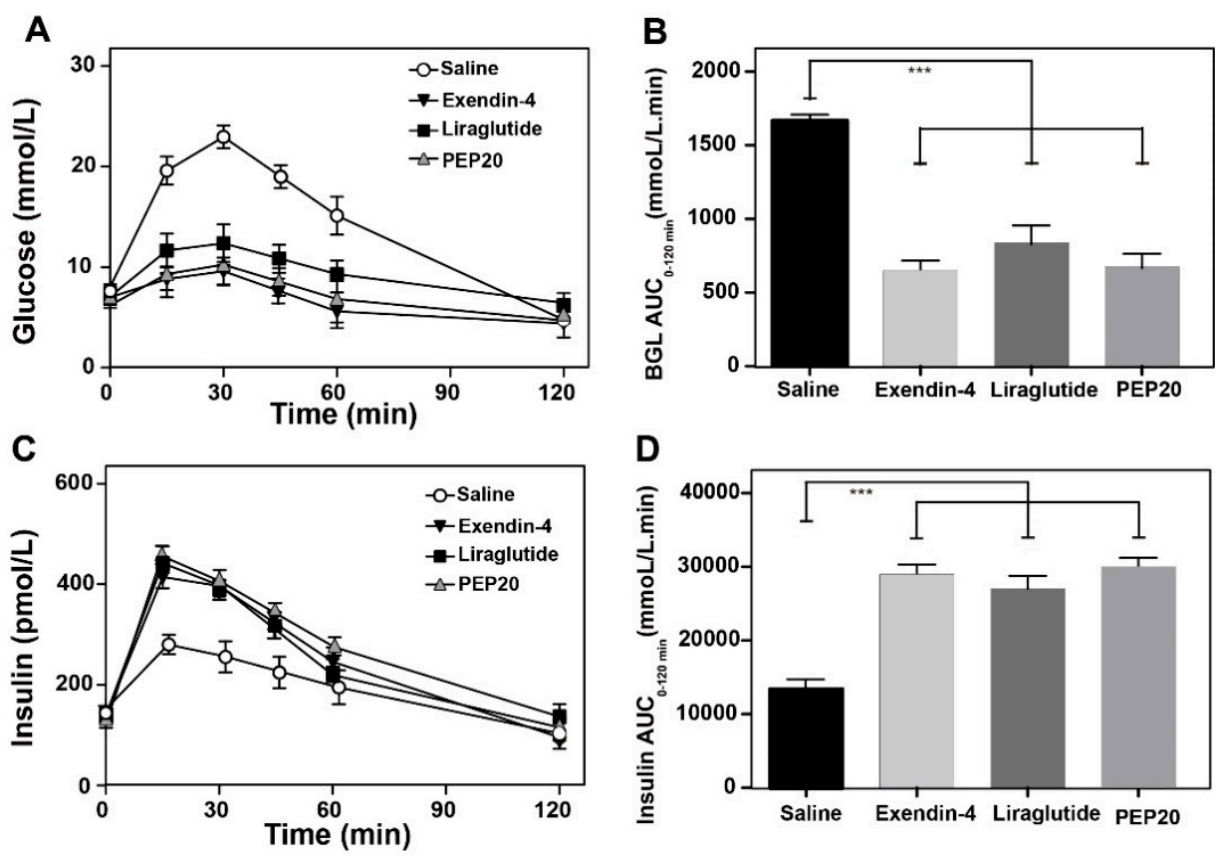

Figure 3. Insulin secretion and glucose tolerance tests in diabetic mice. (A) Glucose-lowering and (B) insulinotropic activities of Exendin-4, Liraglutide, and PEP20 $(25 \mathrm{nmol} / \mathrm{kg})$ in diet-induced obesity (DIO) mice. (C) Area under the curve (AUC) glucose and (D) $\mathrm{AUC}_{\text {insulin }}$ after oral glucose administration. Results are presented as means $\pm \mathrm{SD}$ ( $n=6$ each group). ${ }^{* * *} p<0.001$.

\subsection{Hypoglycemic Duration Test}

The antihyperglycemic efficacy of PEP20 was investigated in male DIO mice. The BGLs of PEP20 group decreased rapidly to the normoglycemic state $(<15 \mathrm{mmol} / \mathrm{L})$ in $1 \mathrm{~h}$ after the administration of $25 \mathrm{nmol} / \mathrm{kg}$. The lowest BGLs in the PEP20 group were similar to the Liraglutide group (Figure 4A). Moreover, the glucose-lowering effect of PEP20 was maintained up to at least $96 \mathrm{~h}$, but only about $24 \mathrm{~h}$ in Liraglutide treated group. Furthermore, PEP20 significantly lowered the glucose level of $63.8 \%$ for 0-96 h compared with the vehicle group (Figure 4B), while it was only $23.2 \%$ after the Liraglutide treatment. These results revealed PEP20 has better antihyperglycemic efficacy and hypoglycemic duration performance than the commercial Liraglutide at the same dose.
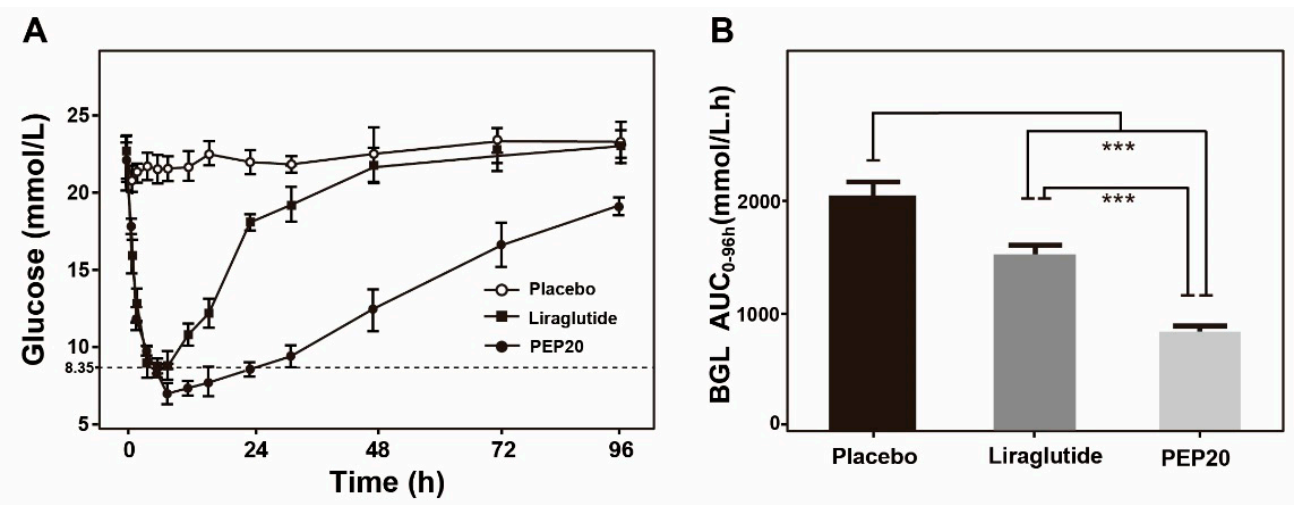

Figure 4. Glucose-lowering and stabilizing effects of Liraglutide and PEP20 were determined by hypoglycemic duration test in DIO mice. (A) Antihyperglycemic efficacies of Liraglutide and PEP20 in DIO mice pretreated with each sample $(25 \mathrm{nmol} / \mathrm{kg}$ ) for $96 \mathrm{~h}$. (B) Hypoglycemic effects of control, Liraglutide and PEP20 based on $\mathrm{AUC}_{0-96} \mathrm{~h}$. Results are presented as means $\pm \mathrm{SD}$ ( $n=6$ each group). $* * * p<0.001$. 


\subsection{Chronic In Vivo Studies}

To further examine the therapeutic potential of PEP20, chronic in vivo studies were performed by a daily subcutaneous (s.c.) injection of PEP20 (25 nmol/ kg) in DIO mice for 4 weeks. As is indicated in Figure 5A,B, the body weight gains and food intake amounts were effectively suppressed in PEP20 treated mice, to a comparable extent to Liraglutide treated ones. Moreover, as is showed in Figure 5C, both PEP20 and Liraglutide treatment resulted in a reduction in HbA1c values $(p<0.001$, $n=6)$ than that in control group.

OGTT tests were performed to evaluate whether a long-term treatment of PEP20 helped to improve the glucose metabolism in DIO mice. The results, graphed in Figure 5D, revealed that there is no significant difference between the area under the curve (AUC) of saline treated group before or after 4 weeks administration. However, we found that the AUC of PEP20 and Liraglutide treated group at 4 weeks decreased $22.1 \%$ or $38.2 \%$ compared with week 0 . These results showed that PEP20 exerted a significant improvement in the glucose metabolism of DIO mice which was similar to Liraglutide, a commercialized GLP-1R agonist.

A

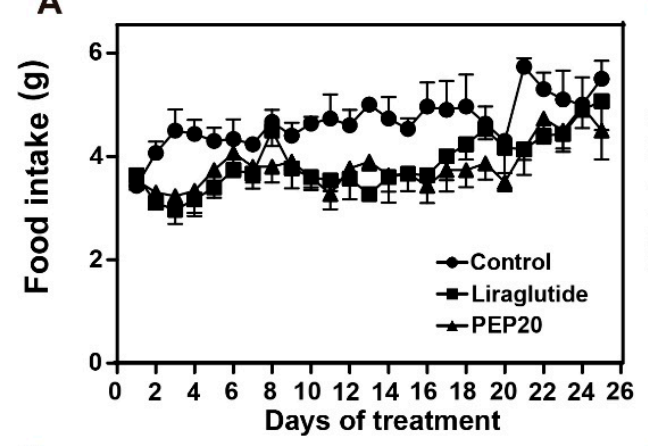

C

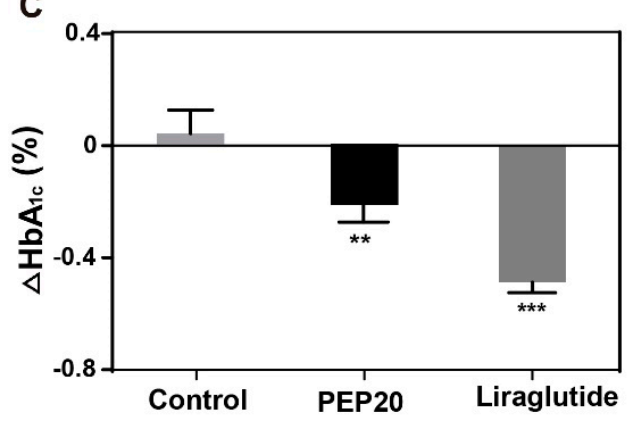

B

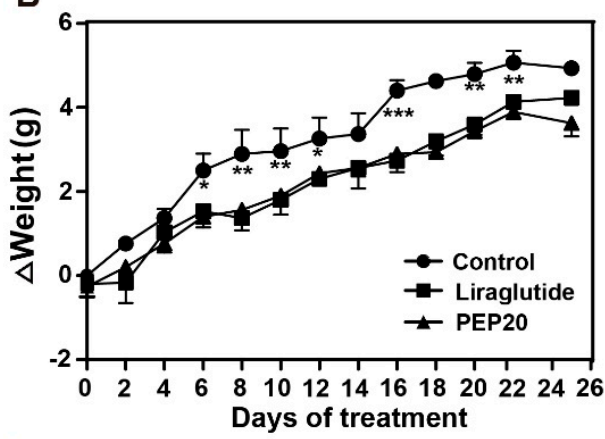

D

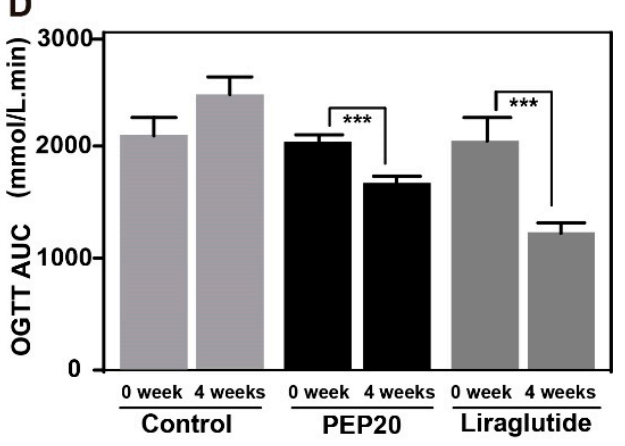

Figure 5. The effects of chronically administered PEP208 on DIO mice. (A) Food intake. (B) Body weight gain. (C) HbA1C. (D) Chronic OGTT AUC. Results are presented as means $\pm \mathrm{SD}(n=6$ each group). ${ }^{*} p<0.05,{ }^{* *} p<0.02,{ }^{* * *} p<0.001$.

\section{Discussion}

G protein-coupled receptor (GPCR) peptide ligands have always been noted for their selectivity, potency, and rapid optimization [26]. Although typically peptides can be developed by chemical synthesis, they have obvious disadvantages, such as a low-throughput process that intrinsically lacks diversity. To address this, we have developed affinity-based screening technologies from a random peptide library with a storage capacity of more than one billion peptides. In the proof-of concept experiments presented here, we show how this methodology allows one to detect and identify novel GLP-1R ligands with unique pharmacology.

GLP-1, an endogenous polypeptide hormone released in response to food intake, potentiate insulin secretion from pancreatic cells through binding and activation of its receptor, and GLP-1R agonists have emerged as treatment options for type 2 diabetes mellitus. [6,18,27]. Although the 
treatments with GLP-1R agonists demonstrate the significant acute or long-term antidiabetic activities [28,29], there were a great many problems such as unavoidable side effects and the homogenization because almost all the related drugs were developed according to the only two native GLP-1R agonists (GLP-1 and Exendin-4) [30-32]. Recently, a novel concept of 'biasing seven-transmembrane receptors', for the developing drugs have been getting increased attention for its potential greater therapeutic effects while possibly avoiding unwanted side effects [33]. The GLP-1R consists of a predicted signal sequence, the ECD of approximately 120 residues, seven membrane-spanning $\alpha$-helices connected by three extracellular and three intracellular loops (the TM domain), and a C-terminal intracellular domain [20]. It is well established that the $\mathrm{N}$-terminal ECD of incretin receptors is important for ligand binding and ligand specificity, whereas the transmembrane domain is involved in receptor activation [15]. Moreover, the GLP-1R ECD, with ligand binding function, can be expressed in both eukaryotic and prokaryotic systems, such as Escherichia coli and mammalian cells $[34,35]$.

Here, a GLP-1R ECD-based system to screen the large phage displayed 12-mer peptide library with the aim of identifying receptor-biased GLP-1R agonists was successfully established (Figure 1). As a result, six 12-mer peptides (PEP01-06) were successfully screened from a large phage displayed peptide library (Table 1). Interestingly, three of the peptides contained a motif of YSSPXA (where $X$ is $\mathrm{S}, \mathrm{A}$, or T), which could enhance its affinity for the receptor. Then the fusion of six selected peptides to the Exendin-4(29-39) was confirmed to significantly enhance their affinity for GLP-1R (Table 1). Considering the predictable short half-life in vivo, we selected the PEP07, with the highest affinity for GLP-1R ECD, as the leader peptide for the further lysine mutagenesis and side chain modification of fatty acid to determine whether different conjugation sites affected the in vitro activity (Figure 2 and Table 2). A series of fatty chain conjugates (PEP17-20) were synthesized and evaluated by in vitro GLP-1R-based cell assays and results PEP20 showed similar effects on the activation of both human and mouse GLP-1R compared to Exendin-4 (Table 4).

It was not only that PEP20 showed similar and comparable promoting insulin secretion ability than Exendin-4 and Liraglutide, respectively, correspond with the in vitro results (Figure 3). The long-acting glucose-lowering effects of PEP20 were further confirmed by the hypoglycemic duration in DIO mice. As we expect, the glucose-lowering effect of PEP20 was maintained up to at least $96 \mathrm{~h}$, which was significant longer than Liraglutide, a commercial GLP-1R agonist (Figure 4). Chronic in vivo studies on DIO mice showed that the body weight gains and food intake amounts were effectively suppressed in PEP20 treated group, to a comparable extent to Liraglutide treated ones (Figure 5A,B). Moreover, as is showed in Figure 5C, both PEP20 and Liraglutide treatment resulted in a reduction in $\mathrm{HbA1c}$ values $(p<0.001, n=6)$ than that in control group. At week 0 , glucose tolerance in both control, Liraglutide and PEP20 treatment group is similar, but at 4 weeks, effect of PEP20 on improvement of impaired glucose tolerance in DIO mice was predominantly compared with vehicle control group (Figure 5D).

Moreover, what deserves more investigation is that PEP20 showed significant better hypoglycemic duration than Liraglutide while both the improvement on the $\mathrm{HbA1c}$ lowering and glucose tolerance of DIO mice were a little weaker than Liraglutide. We hypothesized that might be possibly because that newly designed PEP20 owns a lower sequence homology than Liraglutide compared with native GLP-1 or the coupled fatty chain which lead to a weaker long-term effects on DIO mice. Considering that PEP20, in spite of its prolonged glucose lowering ability, may not the best choice to be a candidate to bring to clinics, we did not further investigate the pharmacokinetic properties of it. Somewhere along the line, we will further to evaluate PEP20 in some other animal model, such as $\mathrm{db} / \mathrm{db}$ mice or optimize the sequence combination (e.g., PEP07 and GLP-1 (9-37)) and fatty chain of PEP20.

In summary, GLP-1R-based binding screening of phage display peptide libraries enabled the discovery of high-potency GLP-1R agonists. A series of preclinical studies demonstrates that the fusion of selected GLP-1R agonist and Exendin-4 (29-39) showed a significant enhancement in the affinity for GLP-1R ECD. Then the further side fatty chain modified hybrid peptide PEP20 showed well 
preserved in vitro receptors activation activity and long-acting in vivo incretin-based antidiabetics. Moreover, chronic in vivo studies on DIO mice also showed that PEP20 is a promising agent deserving further investigation to treat obesity patients with diabetes. Not only that, this strategy may also be applicable to the discovery and design of other GPCR agonists.

\section{Materials and Methods}

\subsection{Materials and Animals}

Ph.D.-12 phage library (New England Biolabs, Beverly, MA, USA) was subjected to biopanning for GLP-1R agonist peptides. All the other peptides, with or without side chain modification, were obtained from Bankpeptide Biological Technology Co. (Hefei, China) used a solid phase method. INS-1 cells were obtained from China Infrastructure of Cell Line Resources (Beijing, China). Male 6to 8-week-old DIO mice were purchased from GenePharma Co., Ltd. (Suzhou, China). Our animal experiments were approved by the Animal Ethics Committee with the approval codes NO. 2017R-131, NO. 2018R-194 and NO. 2018R-263.

\subsection{Phage Display}

The Ph.D.-12 phage library containing linear 12 random peptide sequences with the complexity of $\sim 109$, was applied to discover novel GLP-1R agonist. The GLP-1R ECD, dissolved in 0.01 M PBS ( $\mathrm{pH}$ 7.0), was coated on 96-well plates. Four rounds of screening peptides with high affinity for GLP-1 ECD were conducted according to the instruction of phage library kit. The selected phage was propagated with E. coli ER 2738 strain. The accurate sequences were obtained using the universal primer 96 gIII (5'-CCCTCATAGTTAGCGTAACG -3') for the subsequent DNA sequencing.

\subsection{Characterization of Glucagon-Like Peptide-1 Receptor Agonists}

Molecular weights of GLP-1R agonists were detected using an Autoflex III smartbeam-matrix-assisted laser desorption ionization time-of-flight mass spectrometer (MALDITOF/MS, Bruker, Karlsruhe, Germany).

\subsection{Surface Plasmon Resonance Measurements}

Surface Plasmon Resonance (SPR) measurements were performed with Biacore 8K (GE Health, Boston, MA, USA) for evaluating the associating affinity peptides for GLP1R ECD. Experimental details were carried out according to the Biacore $8 \mathrm{~K}$ user's manual.

\subsection{In Vitro Activity of Glucagon-Like Peptide-1 Receptor Agonists}

INS-1 cells, after two days maintenance, were added with $200 \mu \mathrm{L}$ RPMI 1640 medium free of glucose and then the medium was replaced by a fresh RPMI 1640 added with 2.2 or $16.8 \mathrm{mM}$ glucose and different concentrations of GLP-1R agonists for $2 \mathrm{~h}$. The secreted insulin was detected using a commercial ELISA kit (Merck, Darmstadt, Germany).

\subsection{Oral Glucose Tolerance Tests in Fasted Diet-Induced Obesity Mice}

The male DIO mice received a single subcutaneous injection of saline, Exendin-4, Liraglutide and PEP20 $(25 \mathrm{nmol} / \mathrm{kg})$. Half hour after single dose injection of different samples, the mice were administrated with glucose $(2.0 \mathrm{~g} / \mathrm{kg})$, and then the blood glucose and insulin levels were detected before and at 15, 30, 45, 60 and 120 min by the ELISA kit (Merck).

\subsection{Hypoglycemic Efficacy in Not Fasted Diet-Induced Obesity Mice}

Male DIO mice, with the same average body weight, blood glucose levels and same water and food supply, received a single subcutaneous injection of saline, PEP20 $(25 \mathrm{nmol} / \mathrm{kg})$ or Liraglutide 
(25 nmol/kg). Blood samples were collected from tail veins at different time-points $(0,1,2,4,6,8,12,18$, $24,36,48,72$, and 96 h). BGLs were detected using a one-touch blood glucose meter. Glucose-lowering duration under $8.35 \mathrm{mmol} / \mathrm{L}$ BGL was also checked

\subsection{Chronic In Vivo Studies}

The DIO mice were subcutaneously injected with saline, Liraglutide, PEP20 (25 nmol/ kg) once daily for 4 weeks. Body weight, food intake, and water consumption were measured daily. DIO mice were subjected to OGTT at week 0 and at week 4 to evaluate the advance of diabetic statuses. HbA1c were measured after the treatment using an AU680 automatic biochemical analyzer (Beckman Coulter, Fullerton, Germany).

\subsection{Data Analysis}

Data were analyzed on GraphPad Prism 5 (GraphPad Software, Inc., La Jolla, CA, USA). All measured variables were presented by mean \pm SD. Differences in all parameters were tested via one-way ANOVA; $p$-value $<0.05$ indicates statistical significance.

Author Contributions: Conceptualization, investigation, data processing, and writing-original draft preparation: X.Z. and Z.C.; methodology and experimental operation: Q.C. and W.Z.; writing-review and editing: Z.C.

Funding: This research received no external funding.

Acknowledgments: We thank Tanner Leu (University of Macau) for the insightful and helpful discussion and excellent technical assistance. This work was supported in part by the Inc and published with permission.

Conflicts of Interest: The authors declare no conflicts of interest.

\section{References}

1. Ospina, N.S.; Montori, V.M. Review: In type 2 diabetes, GLP-1 agonists plus basal insulin reduce HbA1c without increasing hypoglycemia. Ann. Intern. Med. 2015, 162, JC6. [CrossRef] [PubMed]

2. Davidson, J.A. Advances in therapy for type 2 diabetes: GLP-1 receptor agonists and DPP-4 inhibitors. Clevel. Clin. J. Med. 2009, 76, S28. [CrossRef] [PubMed]

3. Nauck, M.A.; Vardarli, I.; Deacon, C.F.; Holst, J.J.; Meier, J.J.J.D. Secretion of glucagon-like peptide-1 (GLP-1) in type 2 diabetes: What is up, what is down? Diabetologia 2011, 54, 10-18. [CrossRef] [PubMed]

4. Meier, J.J.; Nauck, M.A. Glucagon-like peptide 1 (GLP-1) in biology and pathology. Diabetes Metab. Res. 2010, 21, 91-117. [CrossRef] [PubMed]

5. Ahrén, B.; Schmitz, O. GLP-1 receptor agonists and DPP-4 inhibitors in the treatment of type 2 diabetes. Horm. Metab. Res. 2004, 36, 867-876. [CrossRef] [PubMed]

6. Meier, J.J. GLP-1 receptor agonists for individualized treatment of type 2 diabetes mellitus. Nat. Rev. Endocrinol. 2012, 8, 728-742. [CrossRef]

7. Ahrén, B. Incretin therapy for type 2 diabetes: GLP-1 receptor agonists and DPP-4 inhibitors. Eur. Diabetes Nurs. 2013, 10, 31-36. [CrossRef]

8. Edwards, K.L.; Stapleton, M.; Weis, J.; Irons, B.K. An update in incretin-based therapy: A focus on glucagon-like peptide-1 receptor agonists. Diabetes Technol. Ther. 2012, 14, 951-967. [CrossRef]

9. Zhong, X.; Yang, S.; Liu, T.; Ji, S.; Hu, J.; Li, H. Engineering a novel protease-based Exendin-4 derivative for type 2 antidiabetic therapeutics. Eur. J. Med. Chem. 2018, 150, 841-850. [CrossRef]

10. Nielsen, L.L.; Young, A.A.; Parkes, D.G. Pharmacology of exenatide (synthetic exendin-4): A potential therapeutic for improved glycemic control of type 2 diabetes. Regul. Pept. 2004, 117, 77-88. [CrossRef]

11. Young, A.A.; Gedulin, B.R.; Bhavsar, S.; Bodkin, N.; Jodka, C.; Hansen, B.; Denaro, M. Glucose-lowering and insulin-sensitizing actions of exendin-4: Studies in obese diabetic (ob/ob, db/db) mice, diabetic fatty Zucker rats, and diabetic rhesus monkeys (Macaca mulatta). Diabetes 1999, 48, 1026-1034. [CrossRef] [PubMed]

12. Göke, R.; Fehmann, H.C.; Linn, T.; Schmidt, H.; Krause, M.; Eng, J.; Göke, B. Exendin-4 is a high potency agonist and truncated exendin-(9-39)-amide an antagonist at the glucagon-like peptide 1-(7-36)-amide receptor of insulin-secreting beta-cells. J. Biol. Chem. 1993, 268, 19650-19655. [PubMed] 
13. Zhao, L.H.; Yin, Y.; Yang, D.; Liu, B.; Hou, L.; Wang, X.; Pal, K.; Jiang, Y.; Feng, Y.; Cai, X.; et al. Differential Requirement of the Extracellular Domain in Activation of Class B G Protein-coupled Receptors. J. Biol. Chem. 2016, 291, 15119-15130. [CrossRef] [PubMed]

14. Graaf, C.D.; Nijmeijer, S.; Wolf, S.; Ernst, O.P. 7TM Domain Structure of Adhesion GPCRs; Springer International Publishing: Berlin, Germany, 2016; p. 43.

15. Kypreos, M.; Banerjee, T.; Mukherjee, D. G protein-coupled receptors-Potential roles in clinical pharmacology. Cardiovasc. Hematol. Agents Med. Chem. 2014, 12, 29-33. [CrossRef] [PubMed]

16. Flower, D.R. Modelling G-protein-coupled receptors for drug design. Biochim. Biophys. Acta 1999, 1422, 207-234. [CrossRef]

17. George, S.R.; O’Dowd, B.F.; Lee, S.P. G-protein-coupled receptor oligomerization and its potential for drug discovery. Nat. Rev. Drug Discov. 2002, 1, 808-820. [CrossRef] [PubMed]

18. Siu, F.Y.; He, M.; Graaf, C.D.; Han, G.W.; Yang, D.; Zhang, Z.; Zhou, C.; Xu, Q.; Wacker, D.; Joseph, J.S. Structure of the human glucagon class B G-protein-coupled receptor. Nature 2013, 499, 444. [CrossRef]

19. Underwood, C.R.; Parthier, C.; Reedtz-Runge, S. Chapter Nine-Structural Basis for Ligand Recognition of Incretin Receptors. Vitam. Horm. 2010, 84, 251-278.

20. Steffen, R.; Susann, S.; Jan, O.; Christine Bruun, S.D.; Sanne, M.; Ller, K.; Claus Bekker, J.; Kjeld, M.; Jesper, L.; Henning, T.G.; et al. Differential structural properties of GLP-1 and exendin-4 determine their relative affinity for the GLP-1 receptor N-terminal extracellular domain. Biochemistry 2007, 46, 5830-5840.

21. Willard, F.S.; Sloop, K.W. Physiology and emerging biochemistry of the glucagon-like peptide-1 receptor. Exp. Diabetes Res. 2012, 2012, 470851. [CrossRef]

22. Runge, S.; Thogersen, H.; Madsen, K.; Lau, J.; Rudolph, R. Crystal structure of the ligand-bound glucagon-like peptide-1 receptor extracellular domain. J. Biol. Chem. 2008, 283, 11340-11347. [CrossRef]

23. Underwood, C.R.; Garibay, P.; Knudsen, L.B.; Hastrup, S.; Peters, G.H.; Rudolph, R.; Reedtz-Runge, S. Crystal structure of glucagon-like peptide-1 in complex with the extracellular domain of the glucagon-like peptide-1 receptor. J. Biol. Chem. 2010, 285, 723-730. [CrossRef] [PubMed]

24. Parthier, C.; Kleinschmidt, M.; Neumann, P.; Rudolph, R.; Manhart, S.; Schlenzig, D.; Fanghanel, J.; Rahfeld, J.U.; Demuth, H.U.; Stubbs, M.T. Crystal structure of the incretin-bound extracellular domain of a G protein-coupled receptor. Proc. Natl. Acad. Sci. USA 2007, 104, 13942-13947. [CrossRef] [PubMed]

25. Doyle, M.E.; Theodorakis, M.J.; Holloway, H.W.; Bernier, M.; Greig, N.H.; Egan, J.M. The importance of the nine-amino acid C-terminal sequence of exendin-4 for binding to the GLP-1 receptor and for biological activity. Regul. Pept. 2003, 114, 153-158. [CrossRef]

26. Freedman, N.J.; Lefkowitz, R.J. Desensitization of G protein-coupled receptors. Recent Prog. Horm. Res. 1996, 51, 319-351. [PubMed]

27. Cho, Y.M.; Merchant, C.E.; Kieffer, T.J. Targeting the glucagon receptor family for diabetes and obesity therapy. Pharmacol. Ther. 2012, 135, 247-278. [CrossRef] [PubMed]

28. Gong, N.; Ma, A.N.; Zhang, L.J.; Luo, X.S.; Zhang, Y.H.; Xu, M.; Wang, Y.X. Site-specific PEGylation of exenatide analogues markedly improved their glucoregulatory activity. Br. J. Pharmacol. 2011, 163, 399-412. [CrossRef] [PubMed]

29. Drucker, D.J.; Nauck, M.A. The incretin system: Glucagon-like peptide-1 receptor agonists and dipeptidyl peptidase-4 inhibitors in type 2 diabetes. Lancet 2006, 368, 1696-1705. [CrossRef]

30. Trujillo, J.M.; Nuffer, W.; Ellis, S.L. GLP-1 receptor agonists: A review of head-to-head clinical studies. Ther. Adv. Endocrinol. Metab. 2015, 6, 19-28. [CrossRef] [PubMed]

31. Saraiva, F.K.; Sposito, A.C. Cardiovascular effects of Glucagon-like peptide 1 (GLP-1) receptor agonists. Cardiovasc. Diabetol. 2014, 13, 142-152. [CrossRef]

32. Filippatos, T.D.; Panagiotopoulou, T.V.; Elisaf, M.S. Adverse Effects of GLP-1 Receptor Agonists. Rev. Diabet. Stud. 2014, 11, 202-230. [CrossRef] [PubMed]

33. Rajagopal, S.; Rajagopal, K.; Lefkowitz, R.J. Teaching old receptors new tricks: Biasing seven-transmembrane receptors. Nat. Rev. Drug Discov. 2010, 9, 373-386. [CrossRef] [PubMed]

34. Maitrepierre, E.; Sigoillot, M.; Le Pessot, L.; Briand, L. Recombinant expression, in vitro refolding, and biophysical characterization of the N-terminal domain of T1R3 taste receptor. Protein Exp. Purif. 2012, 83, 75-83. [CrossRef] [PubMed] 
35. Bazarsurenaa, A.; Grauschopf, U.; Woznyb, M.; Reuschb, D.; Hoffmanncc, E.; Schaefer, W.; Panznerd, S.; Rudolph, R. In vitro folding, functional characterization, and disulfide pattern of the extracellular domain of human GLP-1 receptor. Biophys. Chem. 2002, 96, 305-318. [CrossRef]

Sample Availability: Not available.

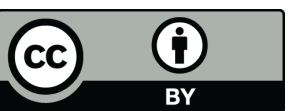

(C) 2019 by the authors. Licensee MDPI, Basel, Switzerland. This article is an open access article distributed under the terms and conditions of the Creative Commons Attribution (CC BY) license (http:/ / creativecommons.org/licenses/by/4.0/). 